\title{
Improving Beginning Teacher Induction Programs through Distance Education
}

\author{
Adrie A. Koehler \& Minchi C. Kim \\ Purdue University, United States
}

\begin{abstract}
Teachers are faced with many barriers during their first few years of teaching, and they desire support to help them through this challenging time. Unfortunately, many beginning teachers rarely receive this assistance. Lack of support can create barriers that grow into to overall job dissatisfaction and lead to the failure of teacher retention. In the past, state departments of education and school administrators have focused on the use of mentoring programs to help address these concerns. However, much inconsistency exists among these programs' duration, structure, and intensity, with many beginning teachers changing schools or leaving the profession all together. The purposes of this paper are to discuss key problems and concerns faced by beginning educators, to explore current professional development practices created for assisting beginning teachers, and to examine new ways to support beginning teachers through the use of educational technologies. Specifically, this article proposes principles to guide the design and improvement of beginning teacher induction programs through the incorporation of distance education technologies.
\end{abstract}

Keywords: Beginning teacher induction; Distance education; Barriers to teaching; Guidelines for the use educational technology in teacher training

\section{Introduction}

Transitioning from a pre-service teacher to a teaching professional can be a very critical and challenging process. University teacher preparation programs have traditionally offered a variety of teaching practices through combining academic and professional experiences. For example, the common elements of pre-service teacher preparation programs include "arts and science courses including an academic major" (Feiman-Nemser, 2001, p. 1019), educational foundations and methods courses, and "supervised practice" (e.g., student teaching, p. 1019).

While pre-service teacher preparation programs may offer foundational experiences and practice, becoming a teacher also requires substantial knowledge and experience that can only be learned in the classroom (Feiman-Nemser, 2001). Thus, the first years of a teacher's career is a vital time for beginning teachers to develop their own "teacher persona," or their personal public teaching identity (McCann \& Johannessen, 2004) and ideas about the kind of teacher they want to be and the methodologies they must employ to become this teacher (Cook, 2009). Additionally, the beginning years of a teacher's career can be influential in overall career success as "the first years 
of teaching are an intense and formative time in learning to teach, influencing not only whether people remain in teaching but what kind of teacher they become" (Feiman-Nemser, 2001, p. 1026).

As they develop this persona and acclimate to the profession, beginning teachers need support (Wiebke \& Bardin, 2009) as they face many challenges during their first years of teaching (Bang, Kern, Luft, \& Roehrig, 2007; Boone \& Boone, 2007; Cook, 2009; McCann \& Johannessen, 2004; Veenman, 1984). Research has shown that beginning teachers encounter challenges with classroom management (Boone \& Boone, 2007; McCann \& Johannessen, 2004; Veeman, 1984), motivation of students (Veeman, 1984), administrative support (Bang et al., 2007; Boone \& Boone, 2007), substandard facilities and equipment (Boone \& Boone, 2007; Veeman, 1984), and vague curriculum ("There's a Hole," 2008), and many will leave the profession after spending only a few years teaching (Boe, Cook, \& Sunderland, 2008; Ingersoll, 2006).

To address and eliminate such barriers, many different types of professional development activities have been employed. Research indicates that well-designed induction programs can make a difference in retaining beginning teachers and promoting student success (Ingersoll \& Kralik, 2004; Ingersoll \& Smith, 2004; Wong, 2004). For example, after examining multi-faceted beginning teacher induction programs across the U.S. that included such features as demonstration classrooms, support-group meetings, mentors, and curriculum facilitators, Wong (2002) found that these school districts experienced decreased attrition rates and were able to create successful support systems for beginning teachers.

Similarly, Ingersoll and Smith (2004) analyzed National Center for Education Statistics' (NCES) Schools and Staffing Survey data and found that as the number of "induction supports" or program activities (e.g., mentor, common planning time, collaboration with others) increased for a beginning teacher, the turnover rate decreased. First-year teachers receiving no induction support had a predicted turnover rate of $40 \%$ compared with an $18 \%$ turnover rate for individuals receiving eight induction supports. Therefore, providing beginning teachers with an appropriate, well-designed support system and professional development during their first years is necessary to promote career success and longevity. Wong (2002) highlights the importance of effective induction programs. "Teachers stay where they feel successful, supported, and part of a team working toward the achievement of common goals" (p. 52).

However, there are two key problems inherent in the common induction professional development activities. First, the main focus of the activities is on completion of formal mentoring that often occurs out of the classroom context, and thus, is disconnected from everyday teaching practice. Many state departments of education, governing K-12 teacher licensure, often mandate beginning teachers to complete some type of mentoring or formal induction program (Ingersoll \& Smith, 2004; Lloyd, Wood, \& Moreno, 2000). Conceptually, over the years, beginning teacher induction has generally referred to planned, intentional, or formal support given to new teachers as they transition into the profession (Bickmore \& Bickmore, 2010; Veeman, 1984).

Beginning teachers will experience the induction process whether a formal program is in place or not (Feiman-Nemser, 2001). During this time period, beginning teachers' "expectations" of teaching are disconnected from the actual experiences that are realized (McCann \& Johannessen, 
2004), and induction activities offered are often disconnected from an "understanding of teacher learning, a vision of good teaching, or a broad view of the role formal induction can play in new teacher development" (Feiman-Nemser, 2001, p. 1031).

Second, although most beginning teachers receive some type of formal induction (Ingersoll \& Smith, 2004), much variation exists in the type of support received, the amount of support received, the method in which the support is received, and generally, the support structure itself (Bartlett \& Johnson, 2010; Bickmore \& Bickmore, 2010; Ingersoll \& Smith, 2004; Wiebke \& Bardin, 2009; Wong, 2004). For example, schools located in rural and urban areas generally face limited resources and experience staffing difficulties (Truscott \& Truscott, 2005). Likely, these difficulties also affect the level of support such schools can provide to beginning teachers. Additionally, limited collaborative opportunities exist for beginning teachers to work with colleagues, resulting in beginning teachers often being "left on their own to succeed or fail within the confines of their own classroom" (Ingersoll \& Smith, 2004, p. 28). Another common problem with induction programs is their rigid structure and inconvenient schedule requirements for beginning teachers (McCann \& Johannessen, 2004).

Overall, the disconnection and inconsistency within and across beginning teacher induction seem to be a problem of access-access to support, resources, flexibility, and collaboration. Due to a lack of consistency and limited offered support in these professional development programs, the needs of beginning teachers often go unmet as these programs do not directly address concerns emerging from the first few years of teaching (Wynn, Carboni, \& Patall, 2007; Ingersoll \& Smith, 2004). One possible way to overcome these barriers and to provide an opportunity for increased access is through the use of distance education technologies. While traditional beginning teacher induction programs often offer support at a school or corporation level, using distance education technologies would allow for a wider network of support and collaboration. At the same time, in order to properly support the needs of beginning teachers via electronic means, the use of distance education technologies must be grounded in sound practices for both induction programs and online learning.

Therefore, the purposes of this paper are: (1) to discuss key problems and concerns faced by beginning educators; (2) to explore current professional development practices created for assisting beginning teachers; and (3) to examine new ways to support beginning teachers through the use of educational technologies. More specifically, this article proposes certain principles to guide the design and improvement of beginning teacher induction programs through the incorporation of distance education technologies.

\section{Background Problem: Disconnection and Inconsistency}

When discussing beginning teacher barriers and beginning teacher induction, there are varied opinions on what qualifies one as a beginning teacher. Veenman (1984) considers beginning teachers as individuals that have taught for three years or less. Some studies summarized in Kagan's (1992) review define beginning teachers as individuals in their first year of teaching, while McCann and Johannessen (2004) point to the first five years of a teacher's career as a "vulnerable time" (p. 138). In this paper, we conceptualize beginning or new teachers as individuals that are 
new to the field of education, with less than five years of teaching experience, and are still at risk for leaving the profession.

Veenman (1984) describes a problem "as a difficulty that beginning teachers encounter in the performance of their task, so that intended goals may be hindered" (p. 143). Other sources use concerns to describe general problems and experiences faced by beginning teachers that can potentially lead to their leaving the profession (Charnock \& Kiley, 1995; McCann \& Johannessen, 2004). By combining ideas from previous research and to provide consistency throughout this review, the term barriers will be used to describe the experiences of beginning teachers that prevent them from successfully accomplishing instructional goals.

\section{Common Beginning Teacher Barriers}

In the past, much research has focused on beginning teacher experiences and the barriers with which beginning teachers face. Several sources discuss the shock experienced by beginning teachers as they take on a teaching career. This initial shock is followed by change and adjustment of behaviors, attitudes, and personality and self-redefining. Often beginning teachers see managing their own classroom very differently than their experiences and expectations as a preservice teacher (Cook, 2009; McCann \& Johannessen, 2004; Veenman, 1984).

Although the experiences of beginning teachers vary, Veenman (1984) as cited by Melnick and Meister (2008) identified the following barriers as most common to beginning educators:

The eight most serious problems that new teachers reported in order of importance were as follows: classroom discipline, motivating pupils, dealing with individual differences, assessing pupils' work, relations with parents, organization of class work, insufficient materials and supplies, and dealing with problems of individual pupils. The next seven in rank order were as follows: heavy teaching load resulting in insufficient preparation time; relations with colleagues; planning of lessons and schooldays; effective use of different teaching methods; awareness of school policies and rules; determining learning level of students; and tied for fifteenth, knowledge of subject matter, burden of clerical work, and relations with principals/administrators (p. 40).

In more recent literature, other major barriers have risen to the top of the list including administrative support, discipline, class preparations, time management, paperwork, and facilities and equipment (Boone \& Boone, 2007; Darling-Hammond, 2003). In a reflection, one beginning secondary educator agonized over vague curriculum, unclear instructional objectives, and intensive time requirement as she attempted to survive her first year of teaching ("There's a Hole," 2008). Another study revealed that beginning English teachers struggle with letting a negative experience set the tone for the entire teaching experience and adjusting to "stressful situations, such as an unruly class, a phone call from an angry parent, or a supervisor's highly critical assessment of a lesson" (p. 140) while handling classroom management issues and fatigue (McCann \& Johannessen, 2004). 
From reviewing these sources, several barriers can be identified that prevent beginning teachers from having successful teaching experiences. Many of the barriers deal with relationships (teacher-to-student, teacher-to-parent, teacher-to-peer, teacher-to-administration, and teacherto-self), management (time, people, and resources), and instructional strategies (motivation, assessment, and methods). Additionally, all of these barriers seem to be in the context of major adjustment, professional self-definition, and personal pedagogical development.

\section{Disconnected and Inconsistent Beginning Teacher Induction Experiences}

Two common factors that contribute to the barriers include disconnection and inconsistency. Beginning teachers' experiences and perceptions are disconnected from and inconsistent with their pre-service experiences. The phenomenon of inconsistency and disconnection is prevalent as pre-service training is not equivalent to managing one's own classroom. After all, beginning teachers are taking on two jobs: "they have to teach and they have to learn to teach" (FeimanNemser, 2001, p. 1026). Therefore, assisting beginning teachers as they acclimate to these new roles is important.

Improving the beginning teacher experience and providing support has been a long-standing concern, and many approaches have been used to address this concern. Teaching experience in the classrooms is of major importance on beginning teachers' perceived preparedness (Melnick \& Meister, 2008). Since beginning teachers typically enter their first fulltime position with limited inclass teaching experience, they need more guidance in their first teaching assignment.

To address this lack of experience, many educational administrators approach acclimating beginning teachers through many different methods. Many states mandate that beginning teachers complete some type of induction program including workshops, orientations, and mentoring (Bartlett \& Johnson, 2010; Ingersoll \& Smith, 2004; Lloyd, Wood, \& Moreno, 2000). In particular, mentoring has been perceived as an important component of induction programs as it promotes teacher retention (Ingersoll and Smith, 2004). Using NCES survey data, Ingersoll and Smith (2004) found if implemented correctly with the appropriate elements, mentoring is highly related to beginning teacher retention and can play a role in preventing beginning teachers from changing schools or leaving the profession. Additionally, after reviewing studies on ten mentoring programs, another analysis found that the programs reviewed had "a positive impact on teachers and their retention" (Ingersoll \& Kralik, 2004, p. 15).

Despite the need for and advantages of such programs, several concerns have been raised. First, these programs do not always address the needs of beginning teachers and are often designed to be more of an assessment process, rather than a support system, resulting in more work for beginning teachers. For example, recently the Indiana Department of Education (IDOE) has changed their Indiana Mentoring and Assessment Program (IMAP) in an attempt to fix previous shortcomings:

In the past, IMAP Year Two Teachers and School Service Personnel had to complete a portfolio in order to satisfy their IMAP requirements. Though the portfolio concept had the best intentions, it was felt by former IMAP Teachers, 
School Service Personnel, Scorers, Mentors, Administrators and the Indiana Department of Education that the portfolio caused a great deal of stress and anxiety and took a great deal of time and energy from the beginning educator. In addition, the results of the portfolio did not really establish whether new teachers and school service personnel were ready for their five-year Proficient Practitioner license (IDOE, 2012).

Although induction initiatives are meant to aid beginning teachers, often times these programs fall short of this goal and add to a beginning teacher's stress and workload. As a result, beginning teachers are less than satisfied with their experiences and left wanting more support.

Second, from one mentoring program to another, much variance exists, including duration, structure, and intensity (Wynn et al., 2007; Ingersoll \& Smith, 2004). In order to effectively serve beginning teachers, induction programs must possess certain attributes that are aligned with the national, state, and local vision for teacher support and preparation and are applicable to everyday teaching practices. Such essential attributes include providing induction support in a bundled format (Wynn et al., 2007; Ingersoll \& Smith, 2004), offering beginning teachers available and reliable mentors from the same field (Ingersoll \& Smith, 2004; Brown, 2001), affording opportunities for professional collaboration (Wynn et al., 2007; Ingersoll \& Smith, 2004; Brown 2001), affording opportunities for lesson observations (Brown, 2001), and supporting psychological, instruction-related, and development needs (Wynn et al., 2007). Additionally, all of this support should be offered in a format that works to alleviate additional stress for beginning teachers (McCann \& Johannessen, 2004) and is easily accessible at any time by beginning teachers (Brown, 2001).

When reviewing the literature surrounding beginning teacher induction, disconnection and inconsistency surfaces again as a commonality affecting the support that beginning teachers receive. Many induction programs provide support in a manner that is disconnected from the beginning teacher literature and inconsistent with the needs of beginning teachers. Additionally, the type and amount of support beginning teachers receive varies greatly from one school to another.

\section{Beginning Teacher Induction as Part of a Professional Learning Continuum}

\section{Two Theoretical Frameworks}

Our analysis of beginning teacher induction is grounded in Feiman-Nemser's (2001) Framework for Teaching Profession Continuum that emphasizes the teaching career as a lifelong process and breaks the profession into three learning phases: pre-service preparation, beginning teacher induction, and ongoing-professional development. As shown in Figure 1, we summarized each phase of the teaching profession with essential features of an ideal teacher education program based on Feiman-Nesmer's (2001) framework. As teaching is a lifelong learning process, providing teachers with "powerful learning opportunities" (p. 1014) at each phase of their career is essential in supporting teachers: 
Learning to teach, especially the kind of teaching reflected in ambitious standards for students and teachers, is a complex lengthy undertaking. It requires coherent and connected learning opportunities that link initial preparation to new teacher induction and new teacher induction to continuing professional development ( $p$. 1048).

\section{Teaching Profession Continuum}

\begin{tabular}{|c|c|c|}
\hline Pre-Service & Beginning & In-Service \\
\hline $\begin{array}{l}\text { Traditional Format: } \\
\text { University Teacher Education } \\
\text { Programs }\end{array}$ & $\begin{array}{l}\text { Traditional Format: } \\
\text { Mentoring, Support-Driven, } \\
\text { Limited Timeframe Programs }\end{array}$ & $\begin{array}{l}\text { Traditional Format: } \\
\text { Required Staff Development \& } \\
\text { Graduate Degrees }\end{array}$ \\
\hline $\begin{array}{l}\text { Promising Program Features: } \\
\text { - Conceptual Coherence } \\
\text { - Purposeful, Integrated Field } \\
\text { Experiences } \\
\text { - Attention to Teachers as } \\
\text { Learners }\end{array}$ & $\begin{array}{l}\text { Promising Program Features: } \\
\text { - Appropriate Assignments } \\
\text { - Developmental Stance, Time } \\
\text { Frame, \& Curriculum } \\
\text { - Integrating Assistance \& } \\
\text { - Assessment } \\
\text { - Strong Mentoring Component } \\
\text { - Partnerships \& Collaboration }\end{array}$ & $\begin{array}{l}\text { Promising Programs: } \\
\text { - Descriptive Review } \\
\text { - "Community of Learners" } \\
\text { Project } \\
\text { - Summer Math for Teachers }\end{array}$ \\
\hline
\end{tabular}

Figure 1. Teaching Profession Continuum Aligned with Essential Features for Teacher Education Programs

Learning to teach takes time, support, and direction over an entire teaching career. Therefore, teachers need appropriate support and opportunities for "powerful learning" (Feiman-Nemser, 2001, p. 1014) at every phase in their career, and professional development efforts should promote continuous growth over time and align the essential supporting features throughout the three phases. The Framework of Essential Factors for Designing Beginning Teacher Program (Figure 2) is provided to identify key elements for beginning teacher induction programs and to illustrate the relationship among them.

In Figure 2, the outermost layer, Appropriate Teaching Assignment \& Professional Development, represents the importance of situating a beginning teacher in "workplace conditions that meet the beginning teacher's need for assisted entry into professional roles, responsibilities, and school norms" (Feiman-Nemser, 2001, p. 1034). To support this goal, beginning teachers may need reduced teaching loads or paired assignments with "strong teachers." Overall, schools should be environments of teacher communities where collaboration is encouraged.

The middle layer, Vision of Good Teaching, illustrates the importance of beginning teachers' using a vision of good teaching to inform induction design. As most induction efforts are not based on a sound "understanding of teacher learning" (Feiman-Nemser, p. 1031), a clear vision and understanding is necessary to guide strategic decision-making and resource alignment in induction programs. 


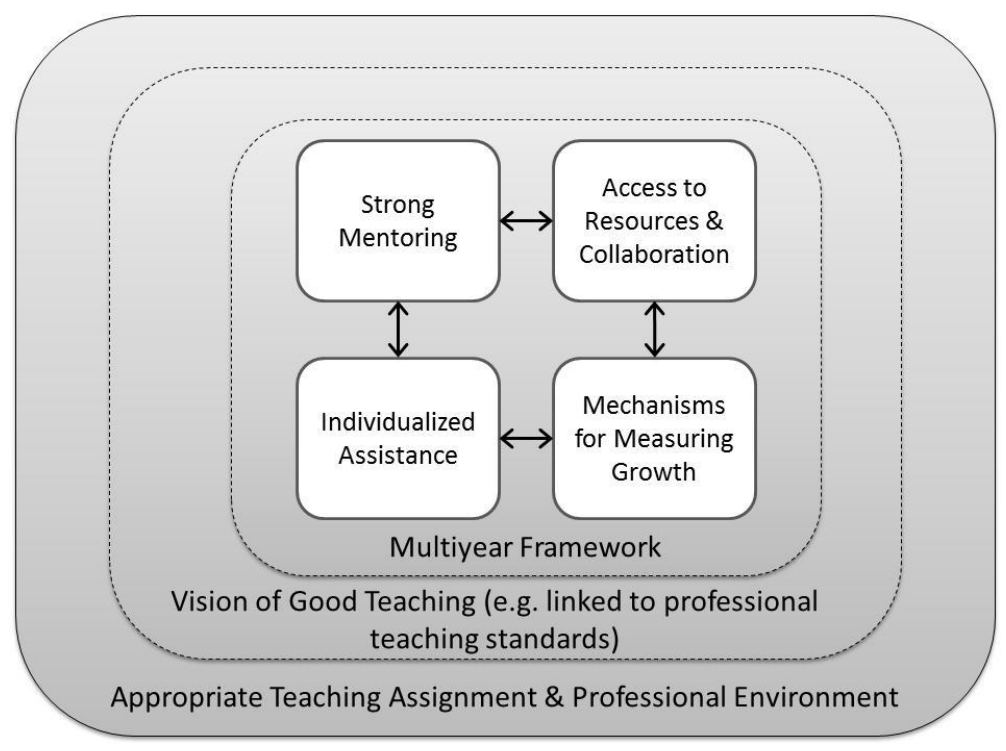

Figure 2. Essential Factors for Designing Beginning Teacher Program

Finally, the innermost layer is representative of a multi-faceted, multiyear support system. As beginning teachers are transitioning into the teaching profession they should have access to strong mentoring, access to resources and collaboration, access to individualized assistance, and access to mechanisms for measuring growth.

\section{Distance Education as a New Direction for Beginning Teacher Induction}

Online learning continues to be a growing area in many different fields. An online format offers individuals options that traditional face-to-face instruction does not. For example, research shows that college students enrolling in online classes did so because online courses offered a convenient schedule, allowed self-pacing and learning on own, and provided access to learning from a distant location (Chen, Gonyea, \& Kuh, 2008; Gaytan \& McEwen, 2007). Additionally, research indicates that "multimedia-based e-learning" (p. 159) can lead to increased student performance and satisfaction when compared to traditional instruction (Zhang, 2005). To further fuel this trend, a recent report from the U.S. Department of Education (2010) discussed two significant findings related to distance education:

- "Students in online conditions performed modestly better, on average, than those learning the same material through traditional face-to-face instruction" (p. xiii).

- $\quad$ "Instruction combining online and face-to-face elements had a larger advantage relative to purely face-to-face instruction than did purely online instruction" (p. xv).

Online learning has been widely used for professional development: "There has been a growing interest in professional online learning in recent years as evidenced by enrollments increasing at the rate of 33\% per year for online learning" (Maor \& Volet, 2007). Many educators seek graduate degrees through online means, and the use of online training has been used in many industries 
including health (Luke et al., 2009; Stone, Barber, \& Potter, 2005), criminal justice (Donavant, 2009), and communications (Maor \& Volet, 2007) to name a few. Additionally, there are several examples of professional development specific to education. Rock et al. (2009) describe coaching techniques using Skype and audio technology, allowing for developing teachers to receive help from individuals many miles away. Keown (2009) found online modules have the potential for professional and community development in social studies education. However, while evidence of using Internet technologies to support beginning teachers appears to be a promising endeavor (D'Aniello, 2004), there is limited information available on this topic as it is still an emerging field.

Many individuals graduating from teacher preparation programs are Digital Natives that have grown up with access to technology and use it often in their daily lives (Prensky, 2001). Prensky (2001) has suggested that students have changed radically and that teachers should be cognizant of this change. Possibly for this reason, many individuals involved with beginning teacher support are turning to new means, specifically electronic, to assist novice teachers (Smith \& Israel, 2010).

In recent years, the use of online tools to support teacher professional development has increased. For example, many websites have been developed with the goal of assisting beginning teachers through the induction process. These websites offer a varied amount of support, tools, and resources, including online workshops, interaction with experts, educational news, lesson plans, and opportunities for collaboration and reflection (Herrington, Herrington, Kervin, \& Ferry, 2006). Other beginning teacher support programs use course management systems that give new teachers access to many resources (Smith \& Israel, 2010).

Specifically, to address beginning teacher induction, many e-mentoring programs are being developed (Smith \& Israel, 2010). Although e-mentoring approaches vary in many ways including the type of technology utilized, the ratio of mentees to mentors, the type of communication techniques employed, and the type of support provided; these programs typically use at least some of the following technology: "computer-mediated communications such as e-mail, discussion boards, chat rooms, blogs, Web conferencing, and growing Internet-based solutions" (Smith \& Israel, 2010, p. 30). Online programs have the potential for assisting beginning teachers to develop professionally, while finding opportunities for leadership and joining a "collaborative community" along the way (Gareis, \& Nussbaum-Beach, 2007).

Similarly, university and induction programs connected through online means have shown promising results. For example, D'Aniello (2004) found successful results following a collaborative project, consisting of a support website, online 3-credit graduate course, and onsite teacher seminar all designed for beginning teachers. Also, "empathetic e-mail" writing (Kelehear, 2002) and e-mail listserv methods (Zuidema, 2012) have been used effectively to promote beginning teacher reflection and development and to provide networks of support. Finally, one middle school principal developed a beginning-teacher-induction wiki that allowed participants to access multiple resources, participate in monthly discussions, and collaborate with others (e.g., peers, university professors, veteran teachers, and school administrators) (Taranto, 2011).

While all of these examples exhibit promising methods, they appear to lack the complete support that beginning teachers need, as illustrated in Figure 2. For example, some emerging methods focus singularly on e-mentoring, while neglecting the other three components necessary for 
strong induction (e.g., access to resources and collaboration; individualized assistance; mechanisms for measuring growth). Although utilizing distance education technology provides many opportunities to correct downfalls of current beginning teacher induction programs, it should not be considered the solution, but rather a tool to be used when working toward achieving goals. Clearly, as new educational technologies are implemented to support beginning teachers, sound principles are needed to guide this process.

\section{How Can Technology Support the Beginning Teacher Experience?}

With many states mandating beginning teachers complete some type of induction program (Ingersoll \& Smith, 2004; Lloyd, Wood, \& Moreno, 2000) ensuring these programs are truly fulfilling the purpose that they serve is crucial. Additionally, some state departments of education, such as Indiana, already have online teacher networks available that provide access to resources and promote collaboration. At the same time, many states are concerned with how they can provide "equity of induction access" to all beginning teachers (Bartlett \& Johnson, 2010).

Online learning tools offer the potential for better serving beginning teachers in their first experiences, where current support practices have been unfavorable. Using lessons learned from traditional mentoring and induction programs and combining the capabilities with online learning technology, future beginning teacher induction programs can provide beginning educators support in ways that are more aligned with their needs, schedule, and convenience. Mentoring and induction program creators should consider using tools such as learning management systems (LMS) and distance education technologies that include many interactive components (e.g., forums, web conferencing, chat, Web 2.0) as they make improvements to current programs.

Additionally, mentoring and induction program facilitators and creators should consider grouping individuals based on the content-area and grade-level that they teach. To ensure that all beginning teachers are receiving proper and consistent support, state departments of education should also consider using online methods to better connect with individuals through sharing information, resources, and assistance. Administering professional development from the state level can help monitor beginning teacher progress and better distribute access to resources.

Using the innermost layer of Figure 2 as a framework, this section discusses how distance education technologies can be used to strengthen mentoring, provide access to resources and collaboration, give individualized assistance, and develop mechanisms for measuring growth in all beginning teacher induction programs. Expanding the Framework of Essential Factors for Designing Beginning Teacher Program (Figure 2), Figure 3 illustrates how distance education should be used in beginning teacher induction, while Table 1 provides an overview of proposed beginning teacher support guidelines. 


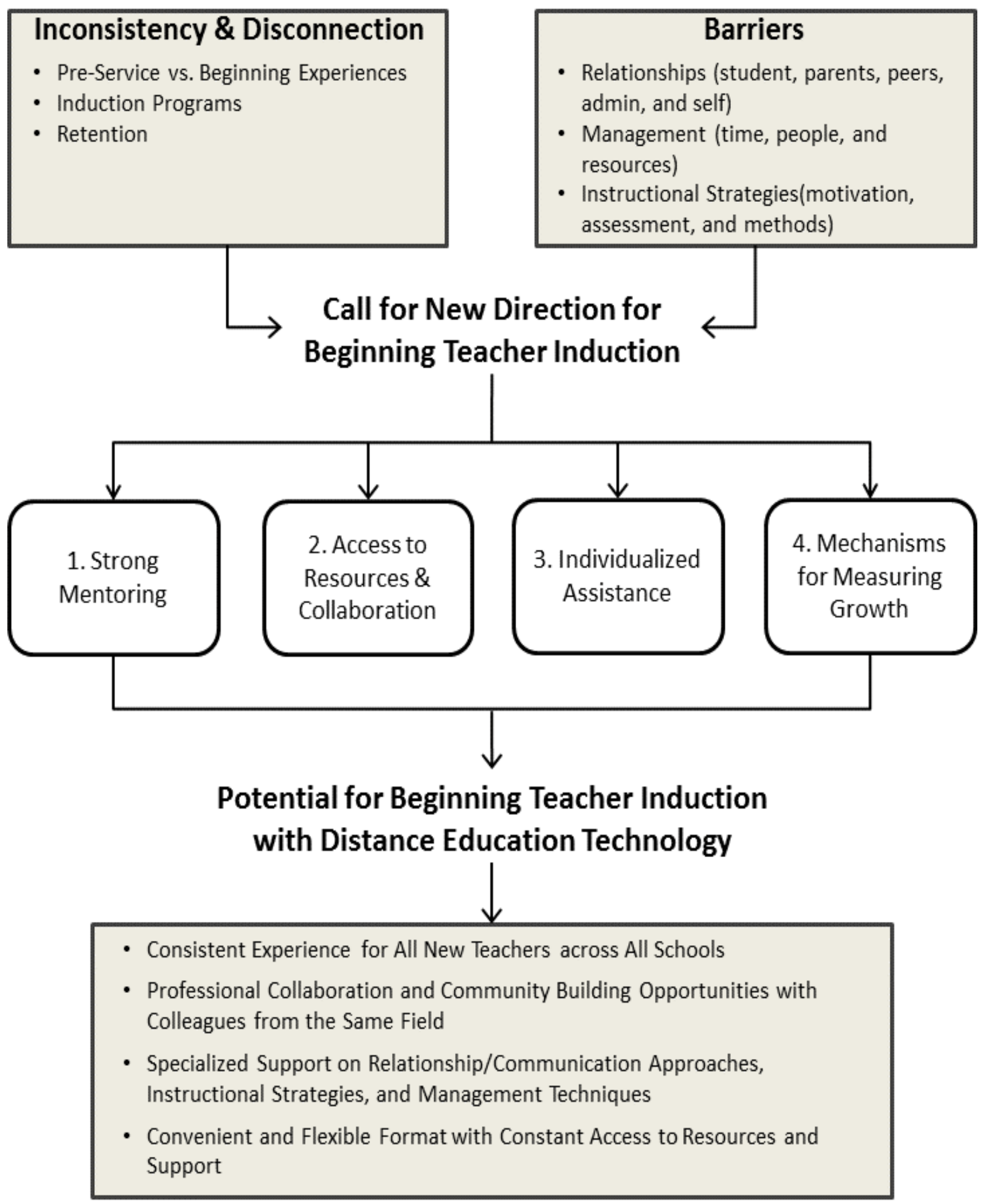

Figure 3. Distance Education Technology in Beginning Teacher Induction 
Table 1. Overview of Proposed Beginning Teacher Support Guidelines

\begin{tabular}{|c|c|c|}
\hline Guideline & Key Characteristics & Distance Education Tools in Action \\
\hline Strong Mentoring & $\begin{array}{l}\text { Mentoring from same } \\
\text { content area } \\
\text { - Mentoring from multiple } \\
\text { sources } \\
\text { Opportunities for mentor } \\
\text { collaboration }\end{array}$ & $\begin{array}{l}\text { LMS and Web communication tools (e.g., } \\
\text { video chat, discussion forums, video } \\
\text { markup): } \\
\text { - connect beginning teachers to peers and } \\
\text { mentors } \\
\text {-connect mentors to other mentors } \\
\text {-provide specialized mentoring support \& } \\
\text { feedback (e.g., same content area pairs) }\end{array}$ \\
\hline $\begin{array}{l}\text { Resources \& } \\
\text { Collaboration }\end{array}$ & $\begin{array}{l}\text { Resources \& collaboration } \\
\text { in a familiar/convenient } \\
\text { format } \\
\text { - Variety in collaborative } \\
\text { tools } \\
\text { - Specialized resources \& } \\
\text { collaboration }\end{array}$ & $\begin{array}{l}\text { Online collaboration tools or resources } \\
\text { promotes convenience of use in a familiar } \\
\text { format } \\
\text { Numerous tools available that promote } \\
\text { specialized resource sharing (e.g., LMS, } \\
\text { DropBox, Pinterest) and collaboration (e.g., } \\
\text { wikis, blogs, chat tools, discussion forums) }\end{array}$ \\
\hline $\begin{array}{l}\text { Individualized } \\
\text { Assistance }\end{array}$ & $\begin{array}{ll}\text { - } & \text { Support consistent with } \\
\text { needs } \\
\text { - } \\
\text { - } \\
\text { Aevelopmental tools } \\
\text { needed }\end{array}$ & $\begin{array}{l}\text { Electronic individual learning plans can be } \\
\text { used to determine beginning teacher needs } \\
\text { and track growth } \\
\text { Educational experts (content, school } \\
\text { location) can connect with beginning } \\
\text { teachers using online tools (e.g., chat tools, } \\
\text { discussion forums) }\end{array}$ \\
\hline $\begin{array}{l}\text { Mechanisms for } \\
\text { Measuring } \\
\text { Growth }\end{array}$ & $\begin{array}{ll}\text { - } & \text { Self-Feedback } \\
\text { - } & \text { Peer-Feedback } \\
\text { - } & \text { Mentor-Feedback }\end{array}$ & $\begin{array}{l}\text { Beginning teachers can reflect individually } \\
\text { (e.g., blogs) or with a mentor } \\
\text { Feedback from peers (e.g., discussion } \\
\text { boards or chat) or mentors (e.g., blogs for } \\
\text { reflecting, video chat for discussions, Jing } \\
\text { or Coach's Eye for individualized coaching) }\end{array}$ \\
\hline
\end{tabular}

\section{Strong Mentoring through Web Technologies}

Although mentoring is often a popular approach to supporting beginning teachers, many mentoring programs are not effective. By utilizing distance education tools, individuals responsible for beginning teacher mentoring programs have the opportunity to provide cohesiveness to such efforts in new ways.

Access to Mentors from Same Field. Much of the research reporting positive results of mentoring programs indicate that beginning teachers had the opportunity to work with individuals 
from their own field. Depending on school size or location, beginning teacher content area and quality of mentor, working with another individual within the same field is not always feasible. Online professional development affords the opportunity to connect individuals from the same fields regardless of distance. Additionally, this format has the potential to allow individuals to complete collaborative work and stay connected with peers, while in a learning community atmosphere.

Access to Multiple forms of Mentoring. Typically, mentoring refers to an experienced teacher being paired with a beginning teacher and the guidance that is provided by the experienced teacher. Although these experienced teacher-beginning teacher relationships can be very beneficial, online tools have the ability to go beyond this traditional relationship to provide even more growth. As Le Cornu (2005) discussed the idea of mentoring has been "reconceptualized" as more of a "collaborative or collegial relationship": "Terms such as comentoring (Bona et al., 1995), mutual mentoring (Landay, 1998), collaborative mentoring (Mullen, 2000) and critical constructivist mentoring (Wang \& Odell, 2002) are being used to reflect these changes" (p. 356). Using communication tools, such as discussion forums, video chat, and email, learners have the opportunity to connect with not only experts in their field, but also to work with other beginning teachers in their field, who are experiencing the same things as they are. The benefits from building such relationships are endless (e.g., guidance on classroom challenges, sharing lesson plans, discussing assessment strategies).

Access to Specialized Mentor Feedback. Besides providing the opportunity of increased connections, distance education technologies also provide an opportunity for different types of communication between mentor and beginning teacher. For example, mentors can provide feedback similar to how coaches review game film by using tools like Coach's Eye or VoiceThread to provide screen markups and audio or text feedback on taped or still shots of beginning teacher experiences. Or, instead of completing observations or demonstrations in traditional face-to-face formats, mentors can create video examples for beginning teachers to view at their own convenience.

Access to Mentoring Collaboration. Finally, "strong programs also bring mentor teachers together" (p. 1037) regularly to discuss and promote deeper understanding of assisting beginning teachers and to further develop their mentoring skills (Feiman-Nemser, 2001). Just as distance education technologies have the potential of connecting beginning teachers with mentors, these same tools can been used to connect mentors over distance or location at times that are most convenient for them in order to improve their mentoring techniques.

\section{Access to Resources \& Collaboration through Online Means}

Wynn et al. (2007) argues that beginning teacher induction must go beyond mentoring and focus on and provide individuals with the opportunity to interact in a professional learning community and defines this as "a group of educators who have shared interests, and, many times, do shared work in an atmosphere in which cognitive and affective aspects necessary for community development are supported" (p. 211). Based on previous research, participation in a learning community may help beginning teachers feel less isolated and more optimistic about teaching (Le 
Cornu, 2005). Additionally, as cited by Le Cornu (2005), "Cochran-Smith and Lytle (1999), for example, stressed that teachers who participate in learning communities often become agents of change in the classroom and school" (p. 359). Using Web technologies can make the learning community a possibility for beginning teacher induction. From interacting with peers and experts in their fields, beginning teachers can build a network of support. For example, social network sites (SNS), discussion forums, wikis, and video-chat are just a few of the tools available that can promote collaboration, and research indicates that SNS tools can be effective in promoting colearning and praxis among pre-service teachers and practitioners (Reich, Levinson, \& Johnston, 2011).

Access to Resources and Collaboration in a Convenient \& Familiar Format. Additionally, one of the greatest advantages of online learning is the convenience factor. With an online format, beginning teachers could access resources and information at a time that is convenient for them. Also, most individuals graduating from teacher preparation programs will be familiar with using a similar format since many of them often communicate using similar methods and probably have taken at least one online course during their college careers. Being familiar with the delivery method can help remove additional stress.

During their first years, beginning teachers have much with which to deal and adjust. Creating their lesson plans and assessment strategies, acclimating to the classroom environment, being assigned additional extracurricular responsibilities, and developing a personal methodology are some of the challenges beginning teachers must handle during their first years of teaching. Instead of creating mentoring and induction programs for beginning teachers that require them to meet at inconvenient times or squeeze into a mentor's busy schedule, online tools can allow beginning teachers to participate and collaborate based on what is best for them.

Access to a Variety of Collaborative Tools. To promote relationship building, several tools can be used. Program facilitators and mentors could lead discussion forums on topics, concerns, challenges, strategies, and successes related to handling and building professional relationships among students, parents, peers, and administration. For example, tips, tools, and techniques that emerge from these discussions and from the beginning teachers' experiences can be used to build a wiki that can be easily accessed and updated. In the process, beginning teachers would have the opportunity to interact with peers and experienced teachers, enhancing their knowledge of relationship dynamics and learn and/or refine their technology skills. In addition, to help build self-growth, beginning teachers could reflect using some type of electronic device (e.g., blog, electronic notebook).

In some instances, beginning teachers are required to complete a portfolio. With numerous online tools from which to choose, beginning teachers could create portfolios using innovative methods (e.g., wikis that include YouTube videos of teaching and links to lesson plan documents), that allow for mentors and educational experts to easily view beginning teachers' work.

Access to More Specialized Resources. Instructional strategies and classroom management can be challenging for beginning teachers. Experienced teachers and field researchers have found methods that work effectively and efficiently when approaching student motivation, instruction, and classroom management. Many of these solutions may be specific to 
content or student age. In a LMS structure with beginning teachers grouped based on their teaching assignment, resources that relate to the specific needs of that group can be stored and accessed easily. Ideas for teaching state standards can be shared and lesson plans and project ideas can be explored, developed, and evaluated. Also, contact information for content and methods experts could be easily accessed.

Additionally, online tools give beginning teachers the opportunity to interact with educational experts. Instead of an expert traveling to different schools to meet with beginning teachers, he or she can meet with several individuals at once in either an asynchronous method (e.g., discussion forum, e-mail) or synchronous method (e.g., chat, webcasts, web conferencing) to discuss concepts and provide advice. These tools give the opportunity for general and content-specific growth to take place as beginning teachers could more easily seek help related to their needsgeneral or content-specific. Approaching mentoring from a content-specific stance is important since attrition rates are higher in some areas than other.

\section{Individualized Assistance Offered via the Internet}

With such a large resource base to examine and select best practices, online-induction programs can be designed in ways that align with the unique attributes and vision of the beginning teacher experience. Additionally, appropriate training can be provided for mentors, and potentially, support can be evenly distributed to all participants, unlike previous methods. Therefore, regardless of school location, socioeconomic status, or size, all beginning educators have the potential of receiving the same type of mentoring and access to the very best resources.

Access to Support Consistent with Needs. During their first years of teaching, beginning educators need their psychological, instruction-related, and development needs supported. Psychological needs can be addressed through assisting beginning teachers with personal and emotional concerns, while "instruction-related" needs focus on giving guidance in fundamentals of lesson planning, school rules, and classroom management" (Wynn et al., 2007, p. 213). Finally, development needs include helping a teacher construct understanding around personal pedagogy and personal professional identity. Online tools can open lines of communication, access, and collaboration to make sure that every beginning teacher at any school in a state has the opportunity to grow in all of these areas. For example, some successful induction programs develop "individual learning plans" for each beginning teacher that can be used to provide support tailored to unique needs and track growth (Feiman-Nemser, 2001).

Providing beginning teachers with a consistent experience can limit school changes; however, if a beginning teacher did seek employment at another school in the state, he or she would still have access to the same resources and mentoring program, without having to acclimate to an entirely new mentoring program, since many of the resources would be accessible through online means. Additionally, some mentoring programs serve to assess beginning teachers, and completion of a mentoring program is necessary for specific license attainment. Using online tools would present many opportunities, including keeping records of a particular beginning teacher's progress. For example, tools such as Google Forms or Spreadsheets allows for easy tracking and collaborative efforts. 
Access to Developmental Tools. Several of the barriers that beginning teachers experience are related to relationship development, instructional strategies, and management techniques. An electronic format could potentially lead to the housing of resources and to focusing discussions all in one place that would be helpful for addressing barriers that are unique to a particular individual's need. Additionally, this format has the opportunity to give beginning teachers access to peers and experts that can help with specific situations, potentially leading to more community building. For example, some instructional strategies may be very specific to a certain field, and an online format would have the capability of connecting individuals with content specific resources-lesson plans and classroom management strategies could be stored and accessed by teachers.

Beginning teacher attrition can affect all schools. However, schools located in urban and rural areas experience higher rates of teacher attrition due to the special conditions that accompany teaching in these locations (MetLife Foundation, 2007; Truscott \& Truscott, 2005). Additionally, certain personality and learning types may be more resistant to change (Overbay, Patterson, \& Grable, 2009). Online tools can also be used to help beginning teachers at urban and rural schools handle the unique challenges with which they are faced or to support specific learning styles. Also, the use of online tools has the potential of providing additional support that beginning teachers clearly need.

Access to Assistance Whenever Needed. Finally, as Brown (2001) found, beginning teachers want an induction program where "help is always available" (p. 74). While this is a difficult task with any induction program, an online format affords more of an opportunity for constant support. As previously discussed, using an LMS can mean a one-stop shop for resources, communication tools, and access to content experts. Online tools provide the potential for support in the evening and during the weekend-whenever the beginning teacher might need help. With help available at their convenience, beginning teachers can gain a sense of confidence and security as they go forward in their professional development. Also, the overall convenient format creates many opportunities for consistency, collaboration, and specialized support across all schools:

Specifically in online or hybrid classes, the professor has the ability to introduce experiences that learners may use to discover new meaning and create new understanding because there are fewer restraints on time. By asking questions that probe experience and application, and by encouraging peer-to-peer interaction faculty may generate profitable extensions of learning (King, 2002, p. 242).

\section{Online Mechanisms for Measuring Growth}

Another important aspect of building a collaborative network is the opportunity for feedback. As measuring growth is an important aspect of beginning teacher induction, feedback plays an important role in this process. Across many academic disciplines, feedback is important "on the learner's perception of ability, performance, motivation, and consequently success" (Tanes, 
Arnold, King, \& Remnet, 2011, pg. 2414), and allows the learner to know whether he or she is "right or wrong" in relation to a specific goal (Smith \& Ragan, 2005). Specifically, considering beginning teacher induction programs, some research indicates that feedback was one of the most helpful aspects of the program (Cuddapah \& Clayton, 2011; Nielson, Barry, \& Addison, 2006). Through the use of online technologies, feedback can be given through three main sources: self, peers, and experienced educational professionals.

Access to Self-Feedback. Beginning teachers can gain feedback from themselves through reflection using blogs or electronic notebooks. As beginning teachers are essentially learning how to teach, "effective teaching requires such reflection in practice, and teachers must demonstrate flexibility in making changes to their teaching" (Romano \& Schwartz, 2005, p. 149). While reflection can take place on an individual level, beginning teachers can also be asked to reflect with a mentor while using a rubric (Nielson, et al., 2006). This technique promotes self-feedback and experienced-professional-feedback.

Access to Peer-Feedback. Peers can provide feedback in the form of mentoring and through discussions (Cuddapah \& Clayton, 2011). In addition, interdisciplinary teams can be an effective tool for beginning teachers to use to gain feedback on teaching issues (e.g., classroom management, Bickmore \& Bickmore, 2010) and to give opportunities for teachers to "analyze and critique each other's work" (Wong, 2004, p. 52).

Access to Mentor Feedback. Finally, mentors or experienced educational professionals can provide coaching and feedback as needed. Through the use of online tools (e.g., blogs for reflecting, video chat for discussions, Jing for individualized coaching), many opportunities exist for giving feedback, as it can be given efficiently and effectively (Gaytan \& McEwen, 2007). Online tools allow for feedback to be shared more easily among different groups, and overall, the sharing encourages growth of the beginning teacher. Beginning teacher progress can also be tracked and feedback given accordingly through the use of an individual learning plan.

Research (Feiman-Nemser, 2001, Wong, 2004) indicates that induction programs should be offered over multiple years. An online format provides the framework for a multiyear induction program to be easily organized and managed. Additionally, as beginning teachers complete the induction process they can still have access to valuable resources and contacts that can continue to assist them as they become a teaching professional.

\section{Discussion and Conclusion}

While distance education tools appear to be a viable option in supporting beginning teachers' needs and are increasingly being used for various educational endeavors, integrating this type of technology comes with challenges, for both the facilitators and the students. For example, lack of funding often prevents distance education undertakings from being initiated and created (OwusuAnsah, Neill, \& Haralson, 2011; Zirkle, Norris, \& Winegardner, 2006). To be most effective, the proposed framework should be implemented at a state department of education level. Considering that government educational efforts are often underfunded, this is a key challenge with the proposed model and guidelines. 
Similarly, the organizing and strategic planning involved with distance education can leave ventures poorly supported (Muilenburg, \& Berge, 2001), and designing an online beginning teacher induction program with the proposed expansive network would take extensive preparations. Finally, once the appropriate distance education framework has been developed, hiring people who possess both the knowledge and technical skills necessary for facilitating online learning can be another concern (Muilenburg, \& Berge, 2001).

Barriers are also present from the student perspective. Access to the appropriate, necessary technologies can be an issue, and in some instances, students feel isolated and disconnected from their peers and instructor in distance learning environments. Considering that a goal of an online beginning teacher induction program is to provide support and connections, creating more feelings of isolation would be detrimental for beginning teachers' growth. Finally, time constraints and time management can also result in barriers to optimal learning online.

While these distance education challenges must be considered when designing an online beginning teacher induction program, the potential benefits far outweigh the costs. For example, although developing an interface that includes all of these features may require both a time and financial investment, turnover is a very costly problem as indicated by a study in Texas: “...the state's annual turnover rate, including a 40 percent turnover rate for teachers in their first three years of teaching, costs a conservative estimate of $\$ 329,000,000$ a year" (Wynn et al., 2007, p. 210). Additionally, since teacher effectiveness improves immensely with a few years of experience, spending time and money is well worth the investment (Darling-Hammond, 2003). Currently, many induction programs are missing key elements, and thus only providing partial support. Utilizing the guidelines set forth in this analysis would provide the necessary strategic framework for developing an online induction program that incorporates the most important features.

Although feelings of isolation are sometimes a concern for students in distance learning environments, not only do the proposed framework and guidelines provide much more support and connections than many traditional induction programs, resources, assistance, and guidance can be given in more diverse, effective ways. Clearly, research is beginning to show a positive impact of distance education technologies on beginning teachers' growth (Gareis \& NussbaumBeach, 2007; Peña \& Almaguer, 2007). However, several issues surrounding teacher induction programs warrant further research.

First, a new, in-depth investigation of common barriers faced by contemporary beginning teachers needs to be completed. Many of the teachers entering the teaching workforce are Digital Natives and more research is needed to determine what, if any, implications that this has for beginning teacher induction programs. Second, a more comprehensive, detailed list of specific distance education technologies that are appropriate for supporting beginning teacher induction and align with the principles discussed in this analysis should be identified. Third, partnerships between beginning teacher induction programs and other institutions need to be explored and developed. In order for the proposed framework to be feasible, beginning teacher induction programs must have connections with and support from state departments of education and institutions of higher education. Finally, more investigation is necessary to examine the feasibility and effectiveness of 
specific tools and to explore learning conditions and contexts in which a beginning teacher induction framework utilizing the guidelines discussed in this paper is enacted.

Professional development that can connect past and new learning experiences in an active manner can be very effective, as adult learners desire "opportunities that directly support their perceived need and address immediate problems or situations" (Feist, 2003, p. 32). This is exactly the type of support beginning teachers need as they transition into the teaching profession. Distance education technology cannot replace a sound program or good mentors and should not be thought of as a standalone solution to a very challenging problem. However, these types of technologies can be instrumental in facilitating the beginning teacher experience and building important relationships. Overall, distance education technologies provide the opportunity for a consistent experience for all beginning teachers across all schools; professional collaboration and community building opportunities with colleagues from the same field; specialized support on relationship/communication approaches, instructional strategies, and management techniques; and a convenient and flexible format with constant access to resources and support.

\section{References}

Bang, E., Kern, A., Luft, J., \& Roehrig, G. (2007). First-year secondary science teachers. School Science and Mathematics, 107(6), 258-261.

Bartlett, L. \& Johnson, L. (2010). The evolution of new teacher induction policy: Support, specificity, and autonomy. Educational Policy, 24(6), 847-71

Bickmore, D. \& Bickmore, S. (2010). A multifaceted approach to teacher induction. Teaching and Teacher Education, 26(4), 1006-1014.

Boe, E. E., Cook, L. H., \& Sunderland, R. J. (2008). Teacher turnover: Examining exit attrition, teaching area transfer, and school migration. Exceptional Children, 75(1), 7-31.

Boone, H. \& Boone, D. (2007). Problems faced by high school agricultural education teachers. Journal of Agricultural Education, 48(2), 36-45.

Brown, K. (2001). Mentoring and the retention of newly qualified language teachers. Cambridge Journal of Education, 31(1), 69-88.

Charnock, B. \& Kiley, M. (1995). Concerns and preferred assistance strategies of beginning middle and high school teachers. San Francisco, California: Paper presented at the annual meeting of the American Educational Research Association. (ERIC Document Reproduction Service No. ED 390 855).

Chen, P., Gonyea, R., \& Kuh, G. (2008). Learning at a distance: Engaged or not?. Innovate: Journal of Online Education, 4(3).

Cook, J. (2009). Coming into my own as a teacher: Identity, disequilibrium, and the first year of teaching. New Educator, 5(4), 274-292.

Cuddapah, J. \& Clayton, C. (2011). Using Wenger's communities of practice to explore a new teacher cohort. Journal of Teacher Education, 62(1), 62-75. 
Darling-Hammond, L. (2003). Keeping good teachers: Why it matters, what leaders can do. Educational Leadership, 60(8), 6-13.

D'Aniello, S. (2004). Using technology to provide new teacher support: A university/district collaborative project. Journal of Special Education Technology, 19(3), 50-54.

Donavant, B. (2009). The new, modern practice of adult education: Online instruction in a continuing professional education setting. Adult Education Quarterly, 59(3), 227-245.

Feiman-Nemser, S. (2001). From preparation to practice: Designing a continuum to strengthen and sustain teaching. Teachers College Record, 103(6), 1013-1055.

Feist, L. (2003). Removing barriers to professional development. T.H.E. Journal, 30(11), 30-36.

Gareis, C. \& Nussbaum-Beach, S. (2007). Electronically mentoring to develop accomplished professional teachers. Journal of Personnel Evaluation in Education, 20(3-4), 227-246.

Gaytan, J., \& McEwen, B. C. (2007). Effective online instructional and assessment strategies. American Journal of Distance Education, 21(3), 117-132.

Herrington, A., Herrington, J., Kervin, L., \& Ferry, B. (2006). The design of an online community of practice for beginning teachers. Contemporary Issues in Technology \& Teacher Education, 6(1), 120-132.

Indiana Department of Education (2012). IMAP assessment information for year two teachers. Retrieved 18 July 2012 from http://www.doe.in.gov/student-services/licensing/imapresponsibilities-building-level-administrators-principals-directors

Ingersoll, R. M. (2006). Understanding supply and demand among mathematics and science teachers. In J. Rhoton \& P. Shane (Eds.), Teaching science in the 21st century (pp. 197-21 1). Arlington, VA; NSTA Press.

Ingersoll, R. \& Kralik, J. (2004). The impact of mentoring on teacher retention: What the research says. Denver, CO: Education Commission of the States. Available at http://www.ecs.org/ clearinghouse/50/36/5036.htm

Ingersoll, R. \& Smith, T. (2004). Do teacher induction and mentoring matter? NASSP Bulletin, $88(638), 28-40$.

Kagan, D. M. (1992, Summer). Professional growth among preservice and beginning teachers. Review of Educational Research, 62(2), 129-169.

Kelehear, Z. (2002). Tell me what went well with your lesson, Sam. Journal of Staff Development, 23(4), 33-36.

Keown, P. (2009). The tale of two virtual teacher professional development modules. International Research in Geographical and Environmental Education, 18(4), 295-303.

King, K. P. (2002). Identifying success in online teacher education and professional development. Internet \& Higher Education, 5(3), 231-246.

Le Cornu, R. (2005). Peer mentoring: Engaging pre-service teachers in mentoring one another. Mentoring \& Tutoring: Partnership in Learning, 13(3), 355-366. 
Lloyd, S. R., Wood, T. A., \& Moreno, G. (2000). What's a mentor to do?. Teaching Exceptional Children, 33(1). p. 38-42.

Luke, R., Solomon, P., Baptiste, S., Hall, P., Orchard, C., Rukholm, E., et al. (2009). Online interprofessional health sciences education: From theory to practice. Journal of Continuing Education in the Health Professions, 29(3), 161-167.

Maor, D. \& Volet, S. (2007). Engagement in professional online learning: A situative analysis of media professionals who did not make it. International Journal on E-Learning, 6(1), 95.

McCann, T. \& Johannessen, L. (2004). Why do new teachers cry?. Clearing House, 77(4), 138.

Melnick, S. \& Meister, D. (2008). A comparison of beginning and experienced teachers' concerns. Educational Research Quarterly, 31(3), 39-56.

MetLife Foundation. (2007, December). Teacher shortages: A policy brief exploring important issues raised by the "2006 MetLife survey of the American teacher: Expectations and experiences." (Policy Brief). Washington, DC: Committee for Economic Development.

Muilenburg, L. \& Berge, Z. L. (2001). Barriers to distance education: A factor-analytic study. American Journal of Distance Education, 15(2), 7-22.

Nielson, D., Barry, A., \& Addison, A. (2006). A model of a new-teacher induction program and teacher perceptions of beneficial components. Action in Teacher Education, 28(4), 14-24.

Overbay, A., Patterson, A. \& Grable, L. (2009). On the outs: Learning styles, resistance to change, and teacher retention. Contemporary Issues in Technology and Teacher Education, 9(3), 356-370.

Owusu-Ansah, A., Neill, P., \& Haralson, M. K. (2011). Distance education technology: Higher education barriers during the first decade of the Twenty-First Century. Online Journal of Distance Learning Administration, 14(2).

Peña, C. M. \& Almaguer, I. (2007). Asking the right questions: Online mentoring of student teachers. International Journal of Instructional Media, 34(1), 105-113.

Prensky, M. (2001). Digital natives, digital immigrants part 1. On the Horizon, 9(5), 1-6.

Reich, J., Levinson, M. \& Johnston, W. (2011). Using online social networks to foster preservice teachers' membership in a networked community of praxis. Contemporary Issues in Technology and Teacher Education, 11(4), 382-397.

Rock, M. L., Gregg, M., Howard, P. W., Ploessl, D. M., Maughn, S., Gable, R. A., Zigmond, N P. (2009). See me, hear me, coach me. Journal of Staff Development, (30)3, 24-6, 28-31.

Romano, M. \& Schwartz, J. (2005). Exploring technology as a tool for eliciting and encouraging beginning teacher reflection. Contemporary Issues in Technology and Teacher, 5(2), 149168.

Smith, P. L. \& Ragan, T. J. (2005). Instructional design (3rd ed.). Hoboken, NJ: John Wiley \& Sons.

Smith, S. J. \& Israel, M. (2010). E-mentoring: Enhancing special education teacher induction. Journal of Special Education Leadership, 23(1), 30-40. 
Stone, D., Barber, C., \& Potter, L. (2005, December 2). Public health training online: The National Center for Suicide Prevention training. American Journal of Preventive Medicine, 2(29). 247-251.

Tanes, Z., Arnold, K., King, A., \& Remnet, M. (2011). Using Signals for appropriate feedback: Perceptions and practices. Computers \& Education, 57(4), 2414-2422.

Taranto, G. (2011). New-teacher induction 2.0. Journal of Digital Learning in Teacher Education, 28(1), 4-15.

There's a hole in state standards and new teachers like me are falling through. (2008). Education Digest: Essential Readings Condensed for Quick Review, 74(2), 22-24.

Truscott, D. M. \& Truscott S. D. (2005). Differing circumstances, shared challenges: Finding common ground between urban and rural schools. Phi Delta Kappan, 87(2), 123-130.

U.S. Department of Education. (2010). Evaluation of evidence-based practices in online learning: A meta-analysis and review of online learning studies. Office of Planning, Evaluation, and Policy Development, Policy and Program Studies Service. Retrieved 20 November 2010 from http://www2.ed.gov/rschstat/eval/tech/evidence-based-practices/finalreport.pdf

Veenman, S. (1984, Summer). Perceived problems of beginning teachers. Review of Educational Research, 54 (2), 143-178.

Wiebke, K. \& Bardin, J. (2009). New teacher support. Journal of Staff Development, 30(1), 34-36, 38.

Wynn, S., Carboni, L., \& Patall, E. (2007). Beginning teachers' perceptions of mentoring, climate, and leadership: Promoting retention through a learning communities perspective. Leadership and Policy in Schools, 6(3), 209-229.

Wong, H. K. (2002). Induction: The best form of professional development. Educational Leadership, 59(6), 52-54.

Wong, H. (2004). Induction programs that keep new teachers teaching and improving. NASSP Bulletin, 88, 41-58.

Zhang, D. (2005). Interactive multimedia-based e-learning: A study of effectiveness. American Journal of Distance Education, 19(3), 149-162.

Zirkle, C., Norris, C., \& Winegardner, A. (2006). Distance education programming barriers in business education teacher preparation programs in the United States. Career \& Technical Education Research, 31(2), 101-118.

Zuidema, L. (2012). Making space for informal inquiry: Inquiry as stance in an online induction network. Journal of Teacher Education, 63(2), 132-146.

Correspondence: Adrie A. Koehler, Learning Design and Technology Program, Department of Curriculum and Instruction, Purdue University, West LaFayette, Indiana, United States 